\title{
Parental Facilitation of Young Children's Technology-based Learning Experiences from Nondominant Groups During the COVID-19 Pandemic
}

\author{
JUNNAN YU, Department of Information Science, University of Colorado Boulder, USA \\ JULISA GRANADOS, University of Colorado Boulder, USA \\ RONNI HAYDEN, ATLAS Institute, University of Colorado Boulder, USA \\ RICAROSE ROQUE, Department of Information Science, University of Colorado Boulder, USA
}

The COVID-19 pandemic has dramatically shifted family life across home, work, and education, especially families from nondominant groups. As schools and other educational programs moved online, parents became the primary facilitators for their children's learning. In this work, we conducted semi-structured interviews with 22 parents from nondominant groups. Insights from interviews highlight the technology-based learning experiences of young children during the pandemic, how parents facilitated these learning experiences, and the challenges parents and children encountered in these learning experiences. We summarize four parental facilitation patterns for children's learning (i.e., designing learning, finding resources, managing, and teaching) and highlight equity issues in distance learning, such as unequal access to learning resources and quality education. Finally, we further reflect on potential solutions to address the challenges parents have reported and share implications for designing technologies that better address children's and parents' needs during a crisis.

CCS Concepts: • Social and professional topics $\rightarrow$ Children; • Applied computing $\rightarrow$ Distance learning; E-learning; Collaborative learning.

Additional Key Words and Phrases: COVID-19; young children; parents; technology-based learning; facilitation; digital inequalities

\section{ACM Reference Format:}

Junnan Yu, Julisa Granados, Ronni Hayden, and Ricarose Roque. 2021. Parental Facilitation of Young Children's Technology-based Learning Experiences from Nondominant Groups During the COVID-19 Pandemic. Proc. ACM Hum.-Comput. Interact. 5, CSCW2, Article 307 (October 2021), 27 pages. https://doi.org/10.1145/3476048

\section{INTRODUCTION}

The Coronavirus Disease 2019 (COVID-19) pandemic has caused a significant disruption to our education systems. According to the United Nations [50], around $94 \%$ of the world's student population and $99 \%$ of students in low and low-middle income countries are impacted by the closures of school buildings and other learning spaces. To support students' continuity of education during the closures of physical learning spaces, schools have adopted distance learning at all levels, accompanied by other innovative support like radio, television, and take-home packages [50].

Authors' addresses: Junnan Yu, Department of Information Science, University of Colorado Boulder, Boulder, CO, USA, junnan.yu@colorado.edu; Julisa Granados, University of Colorado Boulder, Boulder, CO, USA, julisa.granados@colorado.edu; Ronni Hayden, ATLAS Institute, University of Colorado Boulder, Boulder, CO, USA, ronni.hayden@colorado.edu; Ricarose Roque, Department of Information Science, University of Colorado Boulder, Boulder, CO, USA, ricarose@colorado.edu.

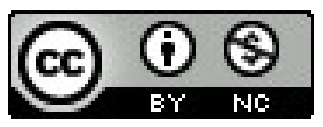

This work is licensed under a Creative Commons Attribution-NonCommercial International 4.0 License.

(C) 2021 Copyright held by the owner/author(s).

2573-0142/2021/4-ART307. https://doi.org/10.1145/3476048

Proc. ACM Hum.-Comput. Interact., Vol. 5, No. CSCW2, Article 307. Publication date: October 2021. 
Even though distance learning makes it possible for children to continue their education at home, challenges have also emerged. First, distance learning has posed an extra burden on parents, especially those with young children who can hardly complete their distance-learning obligations without parental support $[14,31]$. For example, some parents report burn out as they juggle nearly every aspect of their children's learning from printing school work, communicating with teachers, and managing their children's needs [34]. These endeavors can be exhausting for some parents even with one kid, particularly those working parents, and possibly unmanageable for parents with three or four kids $[14,34]$. Additionally, with distance learning, teachers lose the privileges of in-person teaching where students and teachers share the same physical space and teachers can easily monitor students' participation. Instead, students are spread out across different households and connected via audio and/or video, making it hard for teachers to address each student's learning environment and provide personalized support. As such, many parents have become the primary facilitator for their children's learning and need to be involved more than ever. Second, the pandemic is exacerbating existing social and digital inequalities. Researchers have shown that people are unevenly impacted by the pandemic and families from racial/ethnic minority groups have faced the most challenges $[50,53]$. These inequalities have impacted children's learning experiences, such as inadequate access to the Internet or computers for online classes and falling behind during distance schooling [29, 53].

In addition to these challenges, parents face difficulties managing their children's time, which would have been typically filled with opportunities such as summer camps and programming at museums, libraries, and youth clubs - most of which have been shut down or moved online. Subsequently, technologies and media have become the most important learning resources for children in many families. In this study, we aim to explore the technology-based learning experiences of young children and families from nondominant groups during the pandemic and how parents have facilitated these learning experiences. Drawing from education research scholars, we use the term nondominant rather than other descriptors like minority, underserved, or marginalized to call attention to issues of power and power relations [16]. We center on families from nondominant groups because they have been most severely impacted by the pandemic [50,53]. We hope to highlight the challenges these parents and children are facing to access learning opportunities during the pandemic, as well as the possibilities for relevant stakeholders (e.g., schools, teachers, and other learning-resource providers) to design more productive learning experiences and technologies for these families.

We performed semi-structured interviews with 22 parents to investigate their children's technologybased learning experiences during the COVID-19 pandemic. Participants were predominantly Hispanic/Latinx mothers from families with limited financial resources - a large nondominant group. We focus on three research questions in this paper: RQ1. What kind of technology-based learning experiences are young children engaged in during the COVID-19 pandemic? RQ2. How have parents facilitated these learning experiences for their children? RQ3. What challenges have parents and children encountered during learning? Our findings show that participants' children were engaged in four types of technology-based learning experiences during the pandemic, i.e., online schooling, watching educational videos, interacting with educational apps and kits, and developing computer fluency. To facilitate these learning experiences, parents employed different strategies, such as designing learning experiences for children, sitting down together during online classes to help deconstruct class activities, and managing children's time and energy for learning. Simultaneously, parents reported many challenges facilitating their children's learning, e.g., low-quality online classes, impractical teacher expectations, and lacking knowledge and skills to support their children. 
The contributions of this paper are threefold: First, our study provides a qualitative description of children's technology-based learning experiences from parents' perspectives during an emergent crisis, particularly from low socioeconomic status (SES) families, a population group that has received increasing attention from $\mathrm{HCI}$ and $\mathrm{CSCW}$ researchers recently, e.g., [39, 56, 58]. These empirical findings are valuable for educational practitioners and technology designers to discover new learning opportunities for children with limited resources, and to design more accessible and productive learning experiences and technologies that will continue to be relevant even in the post-pandemic landscape. Second, this paper summarizes four parental facilitation patterns and expands the theoretical understanding of parent-child interactions in computer-supported collaborative learning experiences. We examine parental involvement in children's technologybased learning experiences from a facilitation perspective rather than employing the traditional parental mediation theory and its derivative frameworks. Third, we highlight equity issues that families are facing with regards to their children's learning from the perspective of parents, and present design implications for technologies to better address children's learning needs.

\section{RELATED WORK}

This work builds on existing work on parental involvement in children's learning with media and technologies within HCI and CSCW. Therefore, we focus on frameworks and theories describing parent-child interactions around media and technology, which includes Parental Mediation Theory, Joint Media Engagement, and literature on parental facilitation of these interactions. Our work also adds empirical evidence to digital divides in learning, we therefore include relevant work on inequalities in digital access and learning within $\mathrm{HCI}$ and $\mathrm{CSCW}$, particularly literature on families' technology practices from low SES.

\subsection{Parental Mediation Theory and Joint Media Engagement}

Parental mediation refers to the strategies parents take to maximize the benefits and minimize the risks in their children's media use [7,20]. Rooted in parent-child interactions during television watching practices, parental mediation theory classifies parental mediation practices into three categories [7, 19, 46, 54]: restrictive mediation, in which parents set rules to restrict children's media use, such as screen time and access to digital devices; active mediation, in which parents explain or discuss media content with children; and co-using (or co-viewing/co-playing), in which parents engage in media together with their children. As the landscape of digital media has been expanding from television to the Internet, mobile devices, video games, and social media, new parental mediation patterns can also emerge. Therefore, parental mediation theory is a dynamic framework. In the past decade, researchers within Communication and HCI have been expanding the framework or redefining parental mediation practices. For example, Lynn Schofield Clark [7] paid attention to parent roles as a learner and co-creator for children's media engagement and proposed "participatory learning" as a new mediation dimension. In addition to the traditional co-using and restrictive practices, some researchers highlight the parental mediation pattern "monitoring" or "supervising" in children's Internet activity, i.e., parents monitor children's Internet activities like checking their web browser histories and email messages [33, 37]. Instead of following the restrictive, active, and co-using mediation framework, Jiow et al. [20] framed parental mediation practices in children's engagement with video games based on activity purposes: gatekeeping activities (parents restrict children's access and exposure to video games), discursive activities (parents discuss video game content and unsafe online behaviors with children), investigative activities (parents inspect children's video games and seek information to know more about video games), and diversionary activities (parents redirect children into other activities from video gaming, like outdoor play and schoolwork). 
Among these theory-expanding attempts, Joint Mediation Engagement [48] has attracted significant attention and been applied most by HCI researchers (e.g., [39, 46, 47]). Takeuchi and Stevens re-defined "co-viewing" in this digital era as Joint Media Engagement (JME), which refers to the "spontaneous and designed experiences of people using media together" [48, P.9]. JME concentrates on the experiences of people collectively engaging in media, such as viewing, playing, searching, reading, and creating together. JME emphasizes the learning benefits during collective media engagement, particularly within family contexts. For example, parents may play different roles to support their children's development of technology fluency, such as teaching kids how to use technology and collaborating on the same project [3]. On the other hand, JME has been employed to examine family interactions with various types of media within $\mathrm{HCI}$, from interactive videos to digital storytelling and games (e.g., [2, 13, 40]).

Parental mediation theory and JME are powerful tools to examine shared parent-child experiences with media. However, we are hesitant to apply either of them to examine how parents facilitate children's technology-based learning experiences in this study. First, according to the MerriamWebster dictionary, "mediate" is defined as "to work with opposing sides in an argument or dispute in order to get an agreement" and "to get something by working with opposing sides in a dispute." Parental mediation theory originates from parental mediation practices during children's television watching practices and is expanded in the contexts of Internet activities, mobile devices, social media, and video games. These media have both beneficial (e.g., developing technology fluency) and harmful (e.g., media addiction and online safety) impacts on children. Mediation, therefore, is an appropriate phrase to depict parental involvement in their children's use of these consumptionoriented or entertainment-oriented media. Whereas with parental involvement in their children's technology-based learning experiences based on our interview results, we see very few parental practices to mediate the "opposing sides" but mainly to facilitate the learning experiences. Therefore, we believe employing parental mediation theory to structure our analysis of how parents facilitate their children's learning experiences is a misuse of the theory and would not help highlight the supportive practices parents take. Second, JME specifically focuses on shared experiences between people who are involved. Our interview results, however, show that parents are often not directly participating in learning with their children but instead are involved in managing and supporting their learning experiences, e.g., setting up the learning platforms and emailing schoolwork to teachers. As such, JME is inadequate to cover all parents' facilitative practices. Therefore, we decide to follow a grounded theory approach [5] to identify parental facilitation patterns in children's technology-based learning experiences in this paper. In the next section, we focus on the literature about parental facilitation of children's learning with media and technologies.

\subsection{Parental Facilitation of Children's Learning with Technology}

Parental facilitation of children's learning with media and technologies is not something new within $\mathrm{HCI}$ literature. However, such literature is mostly presented from a parent-role perspective, namely what roles parents play in children's learning process. Barron and colleagues [3] identified seven parent roles in children's development of technology fluency, five of which are facilitative: teacher (parents know more than children and teach children how to do something), project collaborator (parents collaborate with children on projects), learning broker (parents seek learning opportunities for children through networking and searching the Internet), resource provider (parents provide resources to children beyond computers), and nontechnical consultant (parents provide suggestion to children on nontechnical issues like artistic design). In young children's learning with computational toys and kits, Yu et al. [61] identified ten parent roles, seven of which are facilitative roles that include: teacher, in which parents teach children how to use a kit and computer programming; collaborator, in which parents and children come up with play ideas together or take turns; executor, 
in which parents help implement children's ideas; scaffolder, in which parents guide the play into meaningful directions; logistics supporter, in which parents provide logistical support like setting up the play; enforcer, in which parents mediate conflicts between sibling and manage children's playtime; and gatekeeper, in which parents explore and test new kits for children. In home-based co-making activities between parents and children, Sadka and Zuckerman [45] classified parent roles into two categories: peer-parent, where parents' goal is to finish an activity regardless of who is leading; and mentor-parent, where parents focus on children's learning process and let children take the lead. Finally, Jones et al. [21] examined parental facilitation practices during parent-child joint engagement in traditional arts, crafts, and digital fabrication activities. They found that parents facilitated children's participation mostly by engaging children in making activities, brainstorming and suggesting ideas, as well as seeking help on behalf of their children.

The aforementioned parent-role literature is predominantly situated in the context of affluent families with middle-to-high incomes. Given that our recruited participants were mostly from low-SES Hispanic/Latinx families, we specifically include literature on how low-SES Latinx parents participate in children's education and interaction with technologies. Note the terms "Hispanic," "Latino," and "Latinx" are all used in the referenced literature to refer collectively to the inhabitants of the United States who are descendants of people from Spain or Latin America. For convenience, we mainly use the term "Latinx" in this paper, but may also use the other two terms interchangeably. Like parents of other ethnic and racial groups, Latinx parents, regardless of socioeconomic status, hold the belief that parental involvement and technologies play essential roles in children's education and can bring many benefits, such as resulting in children's better classroom behaviors and facilitating academic performance like English learning [22, 30, 36, 63]. Therefore, it is not uncommon that Latinx parents encourage and participate in their children's academic tasks (e.g., listening to children's reading and asking questions about homework), as well as purchase technology or adopt broadband to support their children's education $[8,22]$. However, Latinx parents also feel "it [i]s their end of an unspoken agreement with the school to holistically educate the child" [63, P9] and are accordingly involved less in children's formal education than informal education [15]. This unspoken agreement, nonetheless, does not mean these parents feel they can be totally hands-off in regard to their children's school education, but instead assume more of a division of labor between parents and teachers, e.g., parents are responsible for home-based learning like checking if the homework is completed while teachers are responsible for school-based learning like correcting the homework $[8,15,63]$. Importantly, low-SES Latinx parents see the benefits of media and technologies can bring into their children's education and therefore exercise various facilitation practices. These practices include [25, 32, 39, 58]: learning new skills and exploring new media resources for kids, e.g., looking up instructional videos on YouTube for self-education with the aim to support children's academic tasks; learning together with children, such as co-reading e-books, competing with each other in learning new English words, and searching information together; scaffolding children's learning with media like encouraging children to create their own media projects and suggesting activity ideas; and answering children's questions and teaching children new media skills. Additionally, for many low-SES Latinx parents who speak little English, this language barrier is a significant challenge in participating in their children's academic tasks [63]. These parents often feel unqualified and incapable of helping with their children's learning, especially as children progress through middle school and high school where learning materials become increasingly difficult. As a result, children generally experience schoolwork, particularly assignments that require technology, as a solo activity [22].

These different parent roles and practices shed light on the important strategies parents employ to facilitate children's learning with media and technologies. However, we are missing a comprehensive picture of parental facilitation practices and there is no literature within $\mathrm{HCI}, \mathrm{CSCW}$, or Learning 
Sciences that systematically summarizes different parental facilitation patterns, particularly in the context of low-SES families. Additionally, we believe there are new parental facilitation patterns waiting to be discovered, especially with families from non-dominant groups and in the COVID-19 pandemic context where children are learning at home at higher rates than ever in modern schooling history. Therefore, we see the need to keep exploring various parental facilitation patterns and develop a framework to better categorize and describe various parents' facilitative strategies.

\subsection{Digital Inequalities and Socioeconomic Impact on Families' Educational Technology Use}

Parental involvement in children's education, particularly technology-related activities, vary by many factors, such as race/ethnic origin, education level, and income. In this section, we highlight digital inequalities and families' technology practices associated with socioeconomic status. Compared to children in households with more economic resources, children from socioeconomically disadvantaged groups on average have fewer educational and digital resources (e.g., books, computers, and Internet) in their homes [1, 11, 12, 22, 56], with primarily Spanish-speaking households experiencing the least access [30]. Specifically, television and mobile phones remain the dominant form of electronics in low-SES Latinx families for educational content [10, 22]. Low-SES children are found to adopt mobile devices more quickly and also at a younger age than those from higherincome groups $[1,12,22]$. Consequently, low-SES families share devices more often and use mobile phones to access the Internet to a greater extent than their higher-SES counterparts who usually have access to laptops and tablet devices at home [60]. In terms of discovering educational media for children, low-SES parents' experience more challenges searching for resources [8]. Low-SES parents also use significantly less online resources or social network sites to support their children's education [8]. Additionally, Latinx parents may feel insecure about information from actors they are unfamiliar with, e.g., online sources, and are more likely than White parents to distrust information that is not from authoritative venues like teachers $[8,10,58]$. These significant gaps in device access and media resources suggest the media forms and content accessed by low-SES young people differ from their middle-class counterparts, such as the significant amount of television time in the daily lives of Latinx young people [10]. Even though low-SES youth sometimes employ smartphones for creative activities like script writing and photography [56], they are less likely to participate in out-of- and in-school educational enrichment than their higher-income peers $[22,56]$.

In addition to the differences in the access to educational resources, the ways parents participate in their children's digital activities differ significantly across high and low SES groups. Overall, researchers found that parents from low-SES families participate less in their children's educational activities (e.g., reading together) and use less educational resources than parents from high-SES households $[10,15]$. High-SES parents, in contrast, tend to spend more time participating in or shepherding their children's sports, school, and technology related activities, such as leveraging devices like tablets and smartphones to advance their children's language and literacy skills, hosting educational games, providing technology guidance, or leading technology-relevant activities $[8,10,12,15,26]$. These differences in parental involvement can be ascribed to various factors such as access to technical resources, work schedules, and interactions with school systems $[1,8,11,12]$ Additionally, low-SES children cannot rely as much on parental support with technology as their more affluent peers who usually have tech-savvy parents and easier access to the latest technology. Instead, low-SES children often act as their parents' technology helper and teacher, including providing technical assistance (e.g., turning on devices and connecting to the Internet) and helping broker and translate information for parents (e.g., online shopping, visiting doctors, and learning about local resources) [10, 23-26, 30, 39, 43, 44]. Note that despite these differences in parental involvement across socioeconomic statuses, many similarities exist, such as valuing family time

Proc. ACM Hum.-Comput. Interact., Vol. 5, No. CSCW2, Article 307. Publication date: October 2021. 
around technology, deploying digital tools as electronic babysitters or to reward desired behaviors, controlling media access, and monitoring children's media engagement $[1,10,12,36,44,60]$.

To bridge these differences across high and low SES, some Information and Communication Technologies (ICTs) and media strategies have been specifically developed. To name a few, Cho and colleagues [6] designed a SMS subscription service named "Comadre" that texts low-income Latinx parents information on free or low-cost local informal learning opportunities. Wong-Villacres et al. [57] developed and tested a Spanish-speaking chatbot that can automatically derive relevant information from trusted sources like schools and after-school program websites then suggests it to parents in a timely manner. Marsden et al. [35] built a system that allowed Wireless Access Point (WAP) devices to access an HTML-based digital library for people who normally did not have Internet connectivity. However, successfully facilitating adoption and effective utilization of technologies in low-resource educational settings has been found to be challenging [17] and simply providing ICTs is not enough to bridge gaps in learning. High quality educational support and infrastructure are needed, such as training teachers, hiring bilingual liaison staff, providing supplementary teaching materials, and incorporating technologies into the wider curriculum $[49,59,63]$.

The COVID-19 pandemic has significantly magnified existing digital inequalities within the learning and educational systems, especially for families from non-dominant groups [53, 55]. However, details about what these digital divides look like in children's learning during the pandemic are still emerging in literature. As parents shared their children's technology-based learning experiences and how they facilitated these experiences, they also mentioned children's challenges around technologies like digital access and technology fluency. Therefore, our study adds new empirical findings during a difficult time to the long-standing and well-developed digital inequality literature.

\section{METHOD}

We interviewed parents from nondominant groups who had at least one child between 3-13 years old. We focus on this age group because children between this age are attending schools from pre-kindergarten to middle school and may need more support from their parents to access distance learning at home, whereas children attending high school (typically 14 and up) are more independent in both life and education. Parents have also shown to provide less assistance with education as children grow older [63]. All participants were recruited in the Mountain West region of the United States. We focused on families from nondominant groups because evidence shows that people of racial and ethnic minority groups are more severely impacted by the pandemic [53]. We considered three factors when recruiting participants: their education level, their annual household income before the pandemic in 2019 (below $\$ 62,000$, the median household income in 2018 in the US [51], the most recently available data), and their race. We mainly focused on parents from local low-income communities. We recruited our participants in collaboration with a locally based nation-wide nonprofit organization that provides resources to support children's education in low-income communities, and a public library that frequently sent families learning resources during the pandemic. The organizations sent out the study flyers that included both English and Spanish descriptions to local families who were enrolled in their existing programs. Additionally, we asked participants to recommend other parents at the end of each interview.

The data collection included two parts: (1) a short demographic information survey that collected participants' gender, age, race/ethnicity, educational level, number of children, and children's ages and gender; and (2) a 60-90 minute video chat or phone-call interview that focused on their children's learning experiences across Spring 2020 when the pandemic broke out locally to Summer 2020 (i.e., middle of March through August 2020). Most interviews happened in July and August 
Table 1. Participants' Demographic Information

\begin{tabular}{|c|c|c|c|c|c|c|c|}
\hline & Sex & Age & Ethnicity & Education & Language & $\begin{array}{l}\text { Children's } \\
\text { sex and age }\end{array}$ & Family employment status \\
\hline $\mathrm{P} 1$ & $\mathrm{~F}$ & 34 & White & Bachelor & English & $\mathrm{F}(9), \mathrm{M}(4)$ & $\begin{array}{l}\text { Administrative assistant in an educational institution, no } \\
\text { other adults in the household }\end{array}$ \\
\hline $\mathrm{P} 2$ & $\mathrm{~F}$ & 39 & Latinx & Bachelor & Spanish & $\mathrm{F}(14), \mathrm{F}(11), \mathrm{M}(10)$ & $\begin{array}{l}\text { Previously worked in a textile factory but lost the job dur- } \\
\text { ing the pandemic, partner works in construction }\end{array}$ \\
\hline P3 & $\mathrm{F}$ & 38 & Latinx & Bachelor & English & $\mathrm{F}(6)$ & Early child program specialist, partner is a welder \\
\hline $\mathrm{P} 4$ & $\mathrm{~F}$ & 37 & Latinx & Bachelor & Spanish & $M(4.5), M(6)$ & $\begin{array}{l}\text { Part-time project manager, partner is a library program co- } \\
\text { ordinator }\end{array}$ \\
\hline P5 & $\mathrm{F}$ & 28 & White & Bachelor & English & $\begin{array}{l}\mathrm{F}(5), \quad \mathrm{F} \quad(3), \quad \mathrm{F} \quad(10 \\
\text { months) }\end{array}$ & $\begin{array}{l}\text { Stay-at-home mother, partner works in a local police de- } \\
\text { partment }\end{array}$ \\
\hline P6 & $\mathrm{F}$ & 26 & Latinx & High school & English & $\mathrm{F}(6), \mathrm{M}(2)$ & Driver, no other adults in the household \\
\hline P7 & $\mathrm{F}$ & 39 & Latinx & Bachelor & English & M (17), M (16), F (10) & Book-keeper/accountant, partner works in construction \\
\hline P8 & $\mathrm{F}$ & 37 & Latinx & High school & English & $\mathrm{F}(3)$ & $\begin{array}{l}\text { Administrative assistant in a non-profit, partner works in } \\
\text { a local government organization }\end{array}$ \\
\hline P9 & $\mathrm{F}$ & 42 & Latinx & High school & English & $\mathrm{F}(19), \mathrm{F}(7)$ & $\begin{array}{l}\text { Spanish interpreter, partner was a bartender before the pan- } \\
\text { demic and now an artist }\end{array}$ \\
\hline $\mathrm{P} 10$ & $\mathrm{~F}$ & 32 & Latinx & High school & English & $\mathrm{M}(12), \mathrm{F}(11), \mathrm{M}(6)$ & $\begin{array}{l}\text { Worked in residential property management industry, part- } \\
\text { ner's employment information was not disclosed }\end{array}$ \\
\hline $\mathrm{P} 11$ & $\mathrm{~F}$ & 30 & Latinx & High school & English & $\mathrm{F}(6)$ & Financial representative, partner is a graphic designer \\
\hline $\mathrm{P} 12$ & $\mathrm{~F}$ & 33 & $\begin{array}{l}\text { Not } \\
\text { disclosed }\end{array}$ & Bachelor & Spanish & $\mathrm{F}(9)$ & $\begin{array}{l}\text { Previously a cook but lost the job during the pandemic, } \\
\text { partner works in construction }\end{array}$ \\
\hline $\mathrm{P} 13$ & $\mathrm{~F}$ & 44 & Latinx & $<$ High school & Spanish & $\mathrm{F}(19), \mathrm{F}(13), \mathrm{F}(11)$ & $\begin{array}{l}\text { Stay-at-home mother, partner is a purchasing agent for fur- } \\
\text { niture }\end{array}$ \\
\hline $\mathrm{P} 14$ & $\mathrm{~F}$ & 42 & Latinx & Bachelor & Spanish & M (13), M (9) & $\begin{array}{l}\text { Employee in a child education-related organization, no } \\
\text { other adults in the household }\end{array}$ \\
\hline $\mathrm{P} 15$ & $\mathrm{~F}$ & 38 & Latinx & Bachelor & Spanish & M (5), F (3) & Stay-at-home mother, partner is a middle school teacher \\
\hline $\mathrm{P} 16$ & $\mathrm{~F}$ & 39 & Latinx & $<$ High school & Spanish & $F(19), M(16), M(13)$ & Stay-at-home mother, partner works in construction \\
\hline $\mathrm{P} 17$ & $\mathrm{~F}$ & 35 & Latinx & $<$ High school & Spanish & $\mathrm{F}(11), \mathrm{M}(9)$ & Cleaning worker, no other adults in household \\
\hline $\mathrm{P} 18$ & $\mathrm{~F}$ & 24 & Latinx & Bachelor & Spanish & $\mathrm{F}(5)$ & Hotel employee, no other adults in the household \\
\hline P19 & $\mathrm{F}$ & 44 & Latinx & $<$ High school & English & $\begin{array}{l}M(23), F(25), M(23), \\
M(13), F(7)\end{array}$ & $\begin{array}{l}\text { Previously worked in a cafeteria but not working during } \\
\text { the pandemic, partner works in tech company }\end{array}$ \\
\hline $\mathrm{P} 20$ & $\mathrm{~F}$ & 37 & Latinx & Bachelor & Spanish & $\begin{array}{l}M(17), M(15), M(13), F \\
(11), M(9)\end{array}$ & Stay-at-home mother, partner works in a butcher shop \\
\hline $\mathrm{P} 21$ & $\mathrm{~F}$ & 33 & Latinx & Bachelor & Spanish & M (18), M (8) & $\begin{array}{l}\text { Student and stay-at-home mother, partner works in con- } \\
\text { struction }\end{array}$ \\
\hline $\mathrm{P} 22$ & $\mathrm{~F}$ & 43 & $\begin{array}{l}\text { Not } \\
\text { disclosed }\end{array}$ & $<$ High school & Spanish & $\begin{array}{l}\text { F (24), F (18), F (13), F } \\
(10)\end{array}$ & Stay-at-home mother, partner is an auto mechanic \\
\hline
\end{tabular}

2020 when children's learning infrastructure was still under the pandemic mode (i.e., little to no in-person learning opportunities and social-distant public health measures). We interviewed 22 participants who met our criteria, see Table 1. All 22 participants were female, none were were from the same family or from same-sex families. In Table 1, we included the employment information of the participants and their partners (when applicable) using their own languages for describing work Among these participants, ten spoke English and the remaining 12 spoke Spanish. The interviews were conducted using the participants' preferred languages and each participant was compensated with a $\$ 50$ Amazon gift card after the interview. The interview recordings were transcribed by professional audio transcription services, and the Spanish transcriptions were then translated into English by researchers in our team who are fluent in Spanish. 


\subsection{Data Analysis}

The data analysis was structured by our three research questions: the kind of technology-based learning experiences children were engaged in during the pandemic (RQ1), how parents facilitated these learning experiences (RQ2), and the challenges facing parents and children (RQ3). As the first step, the researchers collectively identified segments from the 22 interview transcriptions that reflected children's technology-based learning experiences (408 pieces), parental facilitation (391 pieces), and challenges facing parents and children (433 pieces). Note that some segments fit into multiple categories. For the analysis of the 408 segments about children's technology-based learning experiences (RQ1), we followed the tradition of thematic analysis [4]: two researchers independently coded these segments to identify emergent themes and frequently came together to compare the coding results. Through the inductive coding process, the researchers collectively summarize (i.e., axial coding) the emergent themes around the learning format (i.e., "formal learning" and "informal learning"), learning approaches (i.e., "watching educational videos," "learning with educational apps and kits," "developing computer fluency," and "home schooling"), and learning goals ("school content," "literacy," "math," etc.). We did the same procedure for the analysis of challenges facing parents and children (RQ3): two researchers independently coded the 433 segments about challenges, then came together to compare and refine the themes until disagreements were addressed. Some example themes include "passive participation," "conflicting schedule," and "language barrier." We then completed another round of axial coding to categorize these themes with the aim to better present the challenges in the finding section.

For the analysis of parental facilitation practices (RQ2), we followed a grounded theory approach [5] to identify various facilitation patterns. Two researchers independently coded 149 pieces of parental facilitation segments from 7 randomly selected participants, then came together to compare, refine, and merge the themes, and summarized eight codes (i.e., "designing learning," "finding resources," "instructing," "managing learning," "stepping back," "supporting emotions," "providing technical assistance," and "tracking progress"). After that, two researchers independently coded the remaining 242 segments about parental facilitation practices using the eight codes, achieving Cohen's Kappa score at 0.820 for inter-rater reliability check ("almost perfect agreement" [27]). All disagreements in coding results were discussed between the researchers until consensus was reached. Finally, we performed another round of axial coding for the eight codes and categorized parental facilitation practices into four large categories: "Designing learning," "Finding resources," "Managing," and "Teaching," see Table 2. After finishing coding all the data, we connected our identified facilitation patterns to parental roles reported in the literature about children's learning with technologies, see the most right column of Table 2 . This connection does not mean our identified facilitation patterns are exactly the same as these parent roles but more about certain overlaps. Detailed discussions about these similarities and differences can be found in Discussion. Given the wide child age range in this study, we further compared parental facilitation patterns across children with different age ranges (i.e., preschool, elementary school, and middle school) and reported the comparison results in Findings.

We also checked if our data had reached a theoretical saturation for all three research questions by examining the codes identified from P1 to P22 following an ascending order. Specifically, no new themes for RQ1 were identified after P12 about the types of technology-based learning experiences, learning goals, and technologies involved. For RQ2, all the aforementioned eight facilitation codes could be found from data within P1-P5. And we did not find any new themes about the details of each pattern (i.e., how each pattern was enacted) after P16. For RQ3, almost all codes about challenges could be found within P1-P12, except for one new detail from P16 about the theme of unrealistic teacher expectation. Following Francis et al.'s [9] data saturation principle that a saturation is 
reached when, after 10 interviews, no new themes emerge from three further consecutive interviews, we are confident to claim that our data from 22 participants were saturated for the three research questions. We extracted quotes from all 22 participants rather than those within saturation.

Table 2. Parental Facilitation Patterns of Children's Technology-based Learning

\begin{tabular}{|c|c|c|c|}
\hline Facilitation & Descriptions & $\begin{array}{l}\text { Number of } \\
\text { Participants }\end{array}$ & $\begin{array}{l}\text { Connection to } \\
\text { parent roles }\end{array}$ \\
\hline $\begin{array}{l}\text { Designing } \\
\text { learning }\end{array}$ & $\begin{array}{l}\text { Parents design learning experiences for their children, } \\
\text { such as creating learning tasks, encouraging children } \\
\text { to do learning activities, and helping children review } \\
\text { what has been learned }\end{array}$ & 17 & $\begin{array}{l}\text { Scaffolder[61], } \\
\text { Learning } \\
\text { broker[3] }\end{array}$ \\
\hline $\begin{array}{l}\text { Finding } \\
\text { resources }\end{array}$ & $\begin{array}{l}\text { Parents explore, obtain, and test learning resources for } \\
\text { children, e.g., investigating educational apps and videos } \\
\text { and coordinating resources for learning }\end{array}$ & 16 & $\begin{array}{l}\text { Resource } \\
\text { provider[3], } \\
\text { gatekeeper[61] }\end{array}$ \\
\hline Managing & $\begin{array}{l}\text { Parents manage children's time and energy for learning } \\
\text { (e.g., helping children keep up with school schedules } \\
\text { and providing emotional support), their interaction with } \\
\text { media and teacher (e.g., setting up accounts and operat- } \\
\text { ing learning tools), and tracking their learning progress } \\
\text { (e.g., actively observing class participation) }\end{array}$ & 22 & $\begin{array}{l}\text { Enforcer, } \\
\text { Logistics } \\
\text { supporter, } \\
\text { Spectator } \\
{[61]}\end{array}$ \\
\hline Teaching & $\begin{array}{l}\text { Parents provide guidance and instructions on learning } \\
\text { activities for children, e.g., translating class activities, } \\
\text { teaching new knowledge, demonstrating how to operate } \\
\text { learning tools }\end{array}$ & 19 & $\begin{array}{l}\text { Teacher, } \\
\text { Collaborator } \\
{[3,61]}\end{array}$ \\
\hline
\end{tabular}

\subsection{Limitations}

We see the major limitation of the current study lying in the diversity of our participants. The participants were located in one U.S. state and predominantly Hispanic/Latinx. Additionally, all our participants were mothers. Therefore, our participants do not speak for all parents from nondominant groups. Future studies should attempt to recruit more geographically-, racially-, and gender-diverse participants. However, we did not intentionally recruit all mothers. The results of recruiting resonate with Zamarro et al.'s [62] report on the gender difference in the impact of COVID-19 where mothers, especially from nondominant groups, suffered most job losses and shouldered significantly greater responsibility than fathers for child care and education during the pandemic. Many mothers were also the only ones providing child care in their families. To complement the missing voices of fathers, we purposefully asked participants to describe other adult caregivers' (i.e., fathers) involvement in children's learning and have included this data in the analysis. As such, we used the phrase "parental facilitation" rather than "mother's facilitation" in this paper. We also understand mothers' descriptions of fathers' involvement were another limitation of this study, which could be imprecise or incomprehensive. In addition, our focus on technology-based learning experiences in this paper will inevitably leave behind non-technology learning experiences that could still be relevant to technologies somehow, e.g., parents may learn something from videos but explain it to children a few days later. In this sense, our inclusion of technology-based learning experiences may not be comprehensive, either. Finally, we did not 
specifically collect participants' income-level information and did not know how many families were close to middle income. We inferred that, from the information about their education levels, occupations, number of kids, and interview details, 6 participants' families (i.e., P3, P4, P5, P8, P11, P15) might be closer to middle income and the remaining 16 participants' families were low-income Overall, despite the lack of participant diversity, the parent group in our study is still important because Latinx families make up a large demographic and are the fastest growing minority in the United States [52]. We believe our findings are valuable to understand children's learning experiences from families with limited resources, highlight design opportunities to improve these learning experiences, and deepen the understanding of learning under a rapidly changing but immediate crisis.

\section{FINDINGS}

We report findings of children's technology-based learning experiences, details about parental facilitation patterns in Table 2, and the challenges parents reported during their children's learning in this section.

\subsection{Technology-based Learning Experiences}

During the COVID-19 pandemic, children used technologies in ways that supported learning in and out of school. At the beginning of the pandemic, local schools transitioned to online teaching following the government health policy. As such, children were able to continue their learning of school content. However, many schools limited the number of subjects that were covered during distance learning, mainly focusing on math, science, and literacy. For example, P7 shared that her daughter's school only "focus[ed] on two subjects, which [was] math and language arts." To assist children's distance learning, schools and parents had employed various technologies, including hardware devices (e.g., Chromebook and tablets), digital meeting platforms (e.g., ZOOM and Google Meet), learning management systems (i.e., Seesaw and Canvas), and other assistive tools to facilitate children's learning (e.g., Google Docs/Slides, phone, and Email). Many parents mentioned that they obtained a Chromebook from their children's schools to access online classes. Using the digital learning management systems provided by schools, teachers could publish learning schedules and materials, students could submit their schoolwork and comment on others' work, and parents could see children's learning activities and track their progress. Additionally, parents had utilized other technologies to facilitate their children's distance learning, such as using their phones to take pictures of children's schoolwork and uploading the pictures to Google Drive or emailing them to teachers for submission.

Outside of school-based opportunities, parents leveraged technologies to create learning opportunities for their children. Note that parents and children also used technologies for entertainment and relaxing (e.g., movies and games), and that children often engaged in learning experiences without technologies, which are not the focus of this paper. We identified three kinds of out-ofschool learning experiences with technology: watching educational videos, using educational apps and kits, and developing computer fluency. Many parents explored and subscribed to educational videos (e.g., nature documentaries and videos about numbers, letters, and colors) for their children on various video platforms like TV, Netflix, and YouTube. Some children engaged in learning by playing with educational apps and kits, such as reading E-books, playing mathematical games, and learning on free educational platforms like Khan Academy. Such learning mostly happened on a computer, tablet, or parent's smartphones. Other parents engaged their children in developing computer fluency, such as practicing typing and information searching, because "they [children] are going to use the computer for remote learning again" (P4) for the new academic year. In terms of learning goals, these technology-based learning experiences mainly exposed children to English

Proc. ACM Hum.-Comput. Interact., Vol. 5, No. CSCW2, Article 307. Publication date: October 2021. 
literacy (vocabulary, reading, and writing), mathematical skills (numbers and numerical operations), computer literacy (typing and searching), and other knowledge (e.g., colors, human anatomy, and parents' native languages). In the next section, we present details on how parents facilitated these learning experiences.

\subsection{Parental Facilitation Practices}

When children were engaged in the aforementioned learning experiences, parents adopted various facilitation strategies, which we summarized into four categories: Designing learning, Finding resources, Managing, and Teaching. We present these categories alphabetically and the order does not reflect their relative importance or frequency. We also report findings on the similarities and differences of parental facilitation practices across different age groups.

4.2.1 Designing Learning. Parents created learning opportunities and designed learning experiences for children. Specifically, some parents created learning tasks for their children. For example, P4 created tasks on her computer for her 6-year-old son to practice typing. P15 and her husband designed "some letter and number activities for my [her] younger son to do," P8 would augment her daughter's activities "to prolong or make an extension of whatever activity she's doing, mak[ing] it more challenging." Other parents encouraged literacy activities. P4 shared that she had often "been just encouraging that [reading]" for her daughter during the summer. Some parents asked their children to complete tasks on educational platforms before they could move onto other activities. For example, when her daughter wanted to play with the tablet, P6 sometimes would say, "Okay, well, you need to win a prize on Khan Academy [a learning platform]." At other times, parents needed to be involved at the beginning of their children's learning to help them get into the learning mindset, then gradually stepped back to encourage independent learning. For example, P5 would sit down together with her daughter for online classes, and "once time started going by, I would let her do it by herself." Additionally, some parents helped children review what they had learned, particularly working parents. P11 shared that her husband would ask their daughter to describe what she had learned during the day when coming back from work. We also identified three parental intentions when they created learning experiences for children: (1) to help children learn and become more prepared for future schooling, i.e., acquiring new knowledge and practicing what had been learned; (2) to keep children "occupied and busy" (P2) because parents needed to work, e.g., P7, "Dad and I still have to go to work... what you need to do is to do your work as if you were at school"); and (3) parents' desire for their children to be independent learners.

4.2.2 Finding Resources. Parents explored and provided resources to facilitate children's learning. In some families, parents helped coordinate resources within families to support children's learning. For example, P7 asked her older kids to provide technical support for the youngest one, e.g., Internet connection and logging in and out of meetings. And P3 shared that her family only had one computer for all people when the pandemic started. Subsequently, she woke up at 5:00 am to get her work done before 9:00 am so that her daughter could use the computer for online classes during the day. Additionally, some parents helped obtain physical resources for their children's distance learning, such as picking up learning tools from school (e.g., Chromebook and craft materials), "get [ting] a refurbished Chromebook" (P4), and shopping materials for children's science assignments "at supermarkets during a pandemic" (P15). With out-of-school learning, parents mainly searched and selected educational videos and apps for their children, e.g., "creating a kid's account on Netflix" (P6), finding videos about numbers and letters on YouTube (P1), and "searching [educational apps in] App Store" (P11). When parents explored learning resources, some would review and filter the content. As P5 put it, "For every app I would download, I would do it myself first, and then see if it was good enough for them." Finally, some parents mentioned they were self-educating some technical 
skills with the aim to support their children. For example, P20 did not know "how to log on [to the online classes]" at the beginning of the pandemic but had figured it out for her kids. She also "[had] been learning how to find things [online] to help them [children]."

4.2.3 Managing. Parents were shown to frequently manage children's time and energy for learning, monitoring and tracking their learning progress, and regulating their interactions with media. Many parents shared that they helped their children adapt to the online learning mode and keep up with school schedules. Distance learning left the impression on some young children that they did not need to go to school. P1 shared, "no eight-year-old or nine-year-old third grader wants to wake up to go sit in front of a screen.". As such, some parents "had to explain to him [child] that he was not on break and that he was doing virtual school now" (P15); others "had to wake her [child] up earlier, help her get ready, get her ready to be online" (P18); and some parents were even "begging" their children to "go to online meetings" (P4). After putting their children in front of the screen for online classes, parents needed to help set up learning tools and provide technical assistance for their children's class participation, especially for young children with limited technology fluency. More specifically, many parents helped their children set up accounts on the school's learning platforms and log in and out of these systems. For example, P6 recalled, "we do the password and the username for her [child] every time she logs in." Additionally, parents often helped their young children manipulate learning tools, e.g., opening class webpages, navigating children to different sections, operating the computer mouse, and submitting schoolwork. P3 shared that when her daughter finished school worksheets, she had to help submit them by scanning and emailing them to the teacher. However, not all parents were able to provide such technical support. For example, when her children could not log in to the online class or connect to the Internet, P20 could not provide help and said, "That is what is challenging for me. Like what do I do? What could I do to be able to help them?"

For parents with young children, it was necessary to help structure their children's daily learning activities as it was not realistic to expect young children to be responsible for their learning alone. In practice, some parents created daily schedules for their children or co-create the schedules with children. For example, P11 and her husband "get [got] the schedule out [for their daughter]... like meeting from this time to this time and reading this time"; and P1 shared, "I made her [child] sit down with me and we wrote out a schedule, we posted that schedule in her room, in her space, by her desk." Given children's limited energy, interest, or attention span for an hour(s)-long meeting, parents often kept a close eye on their children's class participation and would take corresponding measures once they noticed any issues. For example, some parents actively observed or frequently checked their children's online learning to see how the children were doing in classes and if the children needed any help. P1 recalled, "we would be sitting in the dining room table. I had my computer on one end, and she [child] had it on the other... So, I could kind of monitor in case she had issues and couldn't get something or needed help with something." And P10 shared, "I go and check up on them every half hour... to make sure that they're doing their work, and make sure they're on their classes." Parents sometimes observed their children's learning from a distance by listening in. For example, P9's daughter usually took online classes in her own room, but P9 and her husband were consistently "listening to the video call."

When parents noticed their children disengaging in class, they would intervene. For example, P9 said that her daughter sometimes left the screen and walked around in the house during online classes, she therefore "would remind her [child] that her class was still going on... she needed to be participating for now, out of respect for her teacher and classmates." While some parents took a more flexible approach and told their children that they could walk around if they needed to move as long as they were listening to what the teacher was talking about (e.g., P3). Additionally, parents 
would provide emotional support for their children's learning. Children, especially young ones, could become frustrated during distance learning as parents explained that it was hard for them to sit in front of a screen for more than 30 minutes in a class, especially when the children were not getting enough attention or support from their teachers and parents. For example, P12 shared that her daughter "got bored of sticking to one thing for so long" and P17's son "got frustrated" when "he did not understand, did not remember [something]" during online classes. In response, some parents would sit down with their children and participate together to help them calm down and focus on learning again. Other parents might redirect their children to other activities or take a break. As P5 shared, "I would just literally try another activity or give them a five-minute break." On the other hand, children did not always need parental supervision and support for learning: sometimes they were self-motivated and able to concentrate on learning activities independently like online classes and schoolwork. As such, parents respected their children's independence. P13 shared that her and her husband tried to be quiet, "so I would not distract them [children]."

Outside of class, some parents would keep track of their children's learning progress and make sure their children kept up with school schedules. For example, some parents often checked in with their children to see if they finished school work on time, e.g., asking children questions like "have you done your homework yet?" (P22). Some parents specifically documented their children's learning activities and progress. P3 mentioned that she used the learning management application Seesaw provided by her daughter's school to write notes of her daughter's learning activities during the summer. Finally, parents managed and regulated their children's interactions with media, such as restricting their children's time spent on other screen-based media like TV programs and educational games because so much of their time was already spent on a screen. Some parents also checked the media history of children's learning tools (e.g., checking browser and video histories) in case the children browsed age-inappropriate content.

4.2.4 Teaching. With this facilitation pattern, parents actively participated in children's learning and provided necessary instructions. Many parents needed to sit down together with their young children during online learning to help read instructions and translate class activities. For example, P8 often repeated what the teachers said for her 3-year-old girl and P3 had to read class activity instructions for her 6-year-old because such a young child "does not know how to read very well and... does not remember a lot" (P17). As such, parents took on the role of a teaching assistant for their young children and would "be right next to him [them], to do everything, and teach him [them]" (P10). At other times, parents taught their children academic content and how to use the learning tools. For example, when her daughter was doing math homework, P11 "would sit there and explain to her"; P5 mentioned walking her daughter through how to join and end a meeting on Google Meet. Some parents would also review their children's schoolwork before submission to make sure their children understand what had been taught. Should they identify any mistakes, they would explain to their children how to do it correctly. Additionally, some parents would use translation applications to understand children's academic tasks, or sought help from teachers for both technical and academic problems, then taught back to their children. For example, P11 would email teachers asking for clarifications on schoolwork problems and the settings of Seesaw, and P20 "call[ed] the school and ask[ed] them what I can do" when her children could not log into online meetings.

4.2.5 Facilitation Practices across Different Age Groups. Given the wide range of children's ages reported in this study, we further examined how parental facilitation practices looked like across children attending preschool (ages around 3-5), elementary school (ages around 6-10), and middle school (ages around 11-13). Among the 22 families, 6 families had at least one preschool child, 16 families had at least one elementary-school child, and 9 families had at least one middle-school

Proc. ACM Hum.-Comput. Interact., Vol. 5, No. CSCW2, Article 307. Publication date: October 2021. 
child. Note that due to the qualitative nature and small sample size of our study, we cannot provide detailed information about the changes of parental facilitation patterns for children of different age groups. However, we are able to see some high-level similarities and differences by simply counting the frequency of each pattern for the three age groups.

As to the similarities, all the identified facilitation patterns can be found in parents' interactions with children across preschool, elementary school, and middle school. In particular, parents were frequently involved in managing children's learning and tracking their progress for all three age groups. With other facilitation practices, the frequency for each age group may vary significantly. More specifically, parents tended to design learning experiences, find educational resources, provide instructions, as well as provide emotional and technical support for their preschool and elementaryschool children more often than for their middle-school children. Parents were also found to step back more from their older children's learning activities, seen most often with parents whose children were in middle school. These differences align with how parents described their different interactions with older and younger kids. For example, P14 shared, "with my older one (13 years old), I almost didn't really help him because he took care of it"; and P17 said, "I would help them [children] a bit, for my daughter (11 years old) a bit less because she is more independent, but my son (9 years old) needed more help."

\subsection{Challenges}

As parents shared their children's learning experiences, they also mentioned many challenges and difficulties they and their children had encountered. In this section, we present a summary of these challenges. Note that different families might have different challenges and the following ordering of these challenges does not reflect their relative importance or frequency.

Young children generally needed extra support from parents to participate in online classes. For example, some parents shared that their children "did not like being on ZOOM much" (P17), "at some point would lose interest" (P9), and "pay attention somewhere else instead of the computer" (P10). Therefore, parents had to help organize and manage their children's learning, such as communicating with teachers about learning schedules, putting children in front of the screen, and disciplining children's class behaviors. Furthermore, some young children lacked the basic technology fluency to participate in online learning independently, like logging in and out of online classes, using the mouse, typing, and uploading assignments to cloud folders. As such, parents needed to be highly involved to provide technical assistance and help the children keep up with learning. However, not every parent was able to do so, especially those whose working time conflicted with their children's school time. P3 shared, "I'm working from about 7 AM to about 4 PM, and a lot of the things and attention she [child] needs are primarily during those hours." Consequently, some parents might not "be aware of what they [children] were doing during the day" (P14) while some parents had to stop doing their work to support their children. P1, who was a single mother, needed to sit down together in her daughter's classes after she got calls from teachers saying her daughter was not participating. Therefore, $\mathrm{P} 1$ had to take a leave of absence from her work because "my stuff was not getting done."

Some parents were concerned about the quality of their children's distance learning. These concerns include unsatisfactory class structure and delivery, reduced subjects being taught, shortened class time, and easy assignments. P22 commented that her child's school "was not prepared for this type of education... [distance learning] was all very badly organized... the teachers only dedicated themselves to uploading tasks, exercises, and reviewing, and that was it." P22 also shared another child's school only provided one-hour of online class time once a week. Similarly, P21 shared that her younger son's online class "was just a time in which they continued to have communication... but academically they no longer did anything." Plus, online learning made it difficult for 
teachers to "see if they [her children] acquired the knowledge or not" (P22) and "know what the kids are really doing" (P16). As a result, some children "fell behind due to online school" (P16), which made their parents worried. Some parents even transferred their children to a different school, e.g., P15, "I changed him to another school... they [the new school] would send us homework for math, science, reading, all of that". Finally, parents were also concerned about the excessive screen their children had for learning and had expected more hands-on learning activities.

It is important to point out that not all parents were concerned about the quality of their children's distance learning. This disparity can be ascribed to the differences in how different schools reacted to the pandemic and adjusted their teaching practices. Even though all participants reported that their children's schools offered distance learning when the pandemic broke out locally, the quality of these experiences across different schools varied significantly. Some schools were able to provide each student with a Chromebook for online classes and mimic the in-person teaching as much as possible, e.g., moving all classes online (including PE and music classes, P8 and P11 for example) and offered the same amount of teaching as in-person. However, some schools did not have computers ready for students to take home, and had to largely reduce the quantity of meeting times and the subjects being taught. Some schools even completely stopped teaching new content and instead used their once-a-week meeting to review what had been covered before the pandemic. Also, some schools were well-prepared and facilitated a smooth transition to online learning for both students and parents, while some had a difficult time reacting to the pandemic, provided little transitional guidance and resources for parents and children, and the teaching became "badly organized" (P22)

Teachers sometimes had high expectations of what children and their parents could do for distance learning under the pandemic. Some parents recalled that when schools switched online, their children's teachers followed a rigid and tight learning schedule, which created a highpressure environment where they were required to help their children keep up with schoolwork. For example, P1 got phone calls from her daughter's teacher saying her daughter did not fill out the morning and afternoon check-in surveys in time. As a working parent, P1 commented that the school schedule "was really rigid... really inflexible," and the calls made her feel her "parenting was being judged." As parents pushed their children to catch up with the learning schedules, tensions in the parent-child relationship might also arise because both parents and children "got very uncomfortable" (P1). Meanwhile, some of the assignments given by teachers were beyond young children's capabilities and parents were forced to do the work together, such as planting and growing a seed, creating PPT presentations, and doing animation projects (e.g., P1 \& P9). P15 commented that such assignments and high parental involvement made her feel "they [the teachers] had us [the parents] be responsible for the education of our son." However, some parents were not well supported by the schools to support their children's learning. For example, P21 expressed how her family was suddenly thrown into new learning systems and tools that "they were not used to," and P16 received only one email from the school telling them "now we're going to use this system, now we're going to do this" when classes moved online. Some parents even "received no response from the school" (P15) when they emailed their questions. To such parents, the school transition process was "so unorganized" (P16) and they were left alone to figure out these tools, transition processes, and how to support learning for their children.

Many parents reported that they, and their children, had little interaction with the teachers and schools. Many parents shared that their children were not getting the needed support and attention from their teachers, e.g., "there were too many kids, and it was only one teacher" (P13). P10 expressed that "they [children] were usually on their own [and]... they were just learning through a computer and not a teacher." P11 added, "she is a first grader, she needs attention". Also, parents described their children sitting silently in front of the screen most of the time and "not having much interaction with other people, with other friends, with other children" (P14). From many parents'

Proc. ACM Hum.-Comput. Interact., Vol. 5, No. CSCW2, Article 307. Publication date: October 2021. 
perspective, it was difficult for their children to participate in online learning. However, not all parents shared this challenge of poor interactions. Some parents felt that the communication with the school was too intense, saying that they received "a billion emails" (P6) and had trouble keeping up with them.

Some parents did not have the necessary resources to support their children's learning. Children's classes, learning tools, and assignments were in English. Parents who did not read and speak English fluently found it challenging to help their children. As P2 shared, "since everything was in English...I could barely help them." Some other parents mentioned that they did not have the knowledge to help their children's learning even though they wanted to. For example, P17 "did not know how to use the computer and everything," so she could not provide any technical support for her kids. And P13 said, "I don't really understand math... those were the times where I would get frustrated, seeing them fail and not being able to help."

Families also needed additional access to technical and material resources to participate in distance learning. Many families were struggling with a poor Internet connection and WIFI quality. For example, P3's daughter "would lose Internet connection once in a while." P16 said her children's online classes often "would freeze." P1 shared, "there is only so much WIFI, but she [daughter] is in a Google meeting, I'm in a Zoom meeting, and the boy is trying to watch TV." Some families could not afford devices for distance learning, e.g., P17 did not have a computer at home before they borrowed one when the pandemic happened and P3 and her daughter had to share one computer for both work and school. Some parents had to prioritize their work to support their family like paying rent and securing food, rather than children's school. P7 shared that she was "an essential worker" but she "wish[ed] I was there more... a parent. I felt terrible and I should have been there [i.e., her daughter's online learning]." P16 said her husband "got sick [COVID-19] at work," then she and her children were all infected. In short, some parents had to "work a full-time job" (P6) and could not provide much support for their children's learning. Finally, space could be another challenge for some families-some families did not have "separate spaces to work" (P4). Subsequently, both children and parents could get distracted when multiple online meetings were happening in the same room at the same time.

\section{DISCUSSION}

In this section, we (1) highlight the equity issues that need more attention from teachers, schools, and other relevant stakeholders like policymakers and governments; (2) connect parental facilitation practices to existing literature, particularly the parental role literature and technology use reported in low-SES families; and (3) provide implications for designing learning experiences and technologies that more closely consider children's and parents' needs.

\subsection{Learning and Challenges during the Pandemic}

Thanks to technology, many of our participants' children were able to continue their school education (i.e., distance learning) and to engage in other technology-based learning opportunities during the pandemic, such as watching educational videos and playing with educational apps. However, the quality of children's experiences differed significantly in our study. Digital access continues to be a significant issue for some families. Nondominant families in the United States have long been shown to own significantly fewer digital resources for children's education than those more affluent families $[1,10,12,30]$. This barrier in digital access became especially prominent during the pandemic, a crisis during which students could not attend school in-person but were connected through digital tools virtually. Fortunately, many parents shared that their children's schools provided take-home computers for online classes. However, not all schools were able to provide take-home devices for children. As such, some families were forced to purchase a 
computer for children's education using their already stretched financial resources, or had to coordinate one device among multiple users at home. Moreover, getting access to devices is only one aspect of accessing quality learning opportunities. Internet connectivity is another big challenge facing many low-SES families. Before the pandemic, nondominant families mainly connect to the Internet through their mobile phones' data plan and have limited access to broadband Internet, especially high quality access $[22,56]$. Therefore, it is not surprising that some parents in our study mentioned that accessing to the Internet caused extra financial burden on their families, and how the unsatisfactory Internet quality disrupted their children's online courses, e.g., freezing videos or disconnection during a meeting. To address these digital inequalities in education, which has been significantly exacerbated by the pandemic, more measures should be taken from the governmental and policy level. Together with Rojin Vishkaie [55], we argue that government as well as non- and for-profit organizations must work in hand to provide inclusive, universal access to digital devices and Internet for students, particularly those from rural and underserved communities, alongside with training more qualified staff who are able to promote education using these digital resources.

Limited parental involvement was another layer of difficulty for many young children in our study. Parents from nondomiant groups are unable to participate in their children's educational activities than more affluent parents due to various reasons like longer working hours and inflexible working schedules $[1,63]$. Likewise, some parents in our study had to prioritize their work to secure basic living needs like food, and therefore were not often able to sit down together with their children. Some parents even brought their young children to their working sites so that they could both work and support their children's learning. In addition to availability, the kind of support some parents in our study could provide was limited. Literature on technology use in nondominant families highlights children's roles as technology and information brokers for their parents who have less English proficiency and technical skills [10, 23, 39]. However, the learning broker role is mostly found among older kids (mainly teenagers) while the majority of kids in our study were young children under age 10, who were still learning how to use various technologies. As parents became the major learning facilitators for distance learning, some nondominant parents had to take on the role of technology teacher for their children in spite of their limited technical skills, such as learning how to run meeting platforms then providing technical assistance. Additionally, previous research shows that for many low-SES Latinx parents, "language was an insurmountable barrier to participation in their children's academic tasks" [63, P9]. Our findings add new empirical evidence to this language obstacle in parents' involvement in children's learning: some parents specifically mentioned they were unable to help, both technically and academically, because they did not understand English. Nonetheless, these parents showed great resilience in the ways they attempted to overcome this language barrier, such as reaching out to Spanish-speaking teachers in their children's schools or using translating applications on their phones.

Sadly, the lack of support for parents and language barriers limited the kind of learning opportunities their children could experience. Compared to more affluent households who frequently identify STEM learning opportunities for their children across different media [18], some parents in our study were not aware of learning opportunities they could leverage on media and technologies, such as educational television programs and apps on their smartphones. As a result, online schooling remained the only technology-based learning opportunity for some children. Knowing that nondominant parents are more likely to rely on teachers as their primary source of information for formal and informal learning [43], schools and teachers can play an essential role to bridge these gaps in learning opportunities for children from nondominant groups by sharing learning resources available on various media with parents and children, such as free videos, educational apps, and events that are relevant to school learning and accessible through basic devices like television and smartphones [57, 58]. Similarly, community-based learning spaces and organizations 
like libraries and museums can also include such learning opportunities and resources in their handouts or newsletters to their audience families.

Our findings also highlight the differences in schools' reactions to teaching during the pandemic. Some schools were able to facilitate a smooth transition to online classes for children and continued to provide quality teaching, whereas some schools had to reduce meeting length and times, even stopped introducing new concepts and activities. These gaps align with long-existing inequalities across schools: low-SES Latinx students are more likely to be enrolled in bigger public schools with less resources than their economically more advantaged Latinx and White peers [11]; even with the same technologies, schools serving privileged students usually use them in more progressive ways than those serving students with less privilege [43]. The COVID-19 pandemic has significantly exacerbated these existing inequalities in the kind of school education low-SES students were receiving. As some parents shared, their children's schools did not communicate well about moving to online classes or provide enough transition guidance, and teaching became lax. On the other hand, there were also issues reported by parents with schools that aimed to provide quality teaching and mimic offline education. These issues include impractical expectations about parents' involvement, rigid learning schedules, and overwhelming communication for online transition. Therefore, both types of school reactions did not fully consider children's learning needs and the availability of parents during the pandemic, resulting in various learning challenges and concerns. Furthermore, parents also shared some other common challenges, i.e., young children's lack of interest and technical fluency for online classes, and too little social interaction with peers and teachers during distance learning. Hopefully, many of these challenges can be addressed or ameliorated by redesigning the distance learning experience, e.g., using a few classes to walk students through how to $\log$ in and out of online meetings and how to submit assignments through emails or cloud drives rather than relying on parents to do it, being more flexible about deadlines, and recording online classes for students who cannot participate in live sessions. As to the issues of children's lack of interest and social interactions with others, teachers can incorporate more hands-on activities into the class, offer shorter but more frequent class times, and pair students with different abilities for group learning. However, these tests and trials will inevitably put extra workload on teachers, it is thus important for teachers as a community to support each other by sharing successful practices and resources.

While this current study is in the context of COVID-19 pandemic, we argue that studying how parents are facilitating learning under this pandemic will inform efforts to better respond to future crises. Researchers argue that "the climate emergency means more pandemics, more fires, more floods, more storms, more interruptions" [41]. For this reason, we must document best practices and challenges, in order to develop a more resilient education system in preparation for future interruptions [41, 42]. In sum, our study uncovered many challenges in young children's remote learning, which will be valuable for relevant stakeholders to redesign policies and learning experiences that better align with children's and parents' needs for future interruptions. Meanwhile, more research is needed to thoroughly understand the ecology of children's learning during this pandemic crisis, such as exploring children's learning experiences from other lenses (e.g., their own perspectives and siblings' perspectives), investigating teachers' experiences [42], and examining schools' reactions to the crisis from a policy level.

\subsection{Parental Facilitation Practices}

To support children's learning, parents employed a variety of facilitation strategies. These strategies include sitting down together in children's online classes, providing instructions for class activities and technical assistance, addressing children's emotional issues, managing children's time and energy for learning, and tracking children's learning progress. Parents also designed learning 
experiences, sought help, and found resources to support their children's education. Among these facilitation practices, some parents applied more practices than others or facilitated more often in certain ways. These differences may be explained by participants' different demographic backgrounds like education levels, employment statuses, and children's ages. For example, some parents could not support their children's online learning because they worked full time during the day, and some parents were not able to design learning experiences or provide technical support due to their limited skills, a lack of resources, or the language barriers between parents and resources. On the other hand, parents' facilitative practices are fluid across different patterns. For example, with respect to "Managing," P1 usually set up her daughter's computer and logged her into online classes (i.e., providing technical assistance), then sat on the other side of the same table and frequently observed the girl's participation in case she needed any help (i.e., actively observing), but intentionally tried not to interrupt her class participation (i.e., stepping back). Additionally, some parents' facilitation practices overlap with Joint Media Engagement (JME) practices, including "Teaching" and some practices under the "Managing" category like providing technical and emotional support. However, not all parents' practices within these patterns are JME. For example, in addressing children's emotional issues, parents sometimes joined online classes and participated together to calm the children down (JME practices) while other times directed the children to other activities or take a break (non-JME practices). Therefore, when applying JME to examine parental involvement in children's media engagement, we must consider the scope of JME and recognize parents' other key practices beyond co-engagement, such as providing logistical support and administering children's media use.

It is important to point out that some parent facilitation practices were not voluntary but instead necessitated by the way the pandemic has changed the learning landscape. Before the pandemic, Annette Lareau [28] found that working and poor families tended to follow the approach of natural growth when parenting, i.e., focusing on children's basic needs like food, shelter, and safety while allowing the children to develop naturally. However, parents in our study were frequently engaged in various roles and strategies to assist their children's education during a time of crisis. For example, young children typically could not be self-sufficient in transition to distance learning, requiring parents to sit down in their children's classes, help translate class activities, and keep the children on task with their learning schedules. Such support required some parents to even take leave from their jobs. This high degree of parental involvement in online schooling does not mean that parents' long-held ideas of their roles and teachers' roles have shifted (i.e., teachers are responsible for in-school learning, while parents are responsible for learning at home [15, 63]). Instead, parents were pressured into taking on additional responsibilities when schools were still figuring out how to fulfill their traditional roles with children's schooling. This finding indicates that the distance teaching approaches that relied on students' independence and self-regulation did not work for young children. As many parents shared, teachers sometimes had unrealistic expectations about what they and their young children were able to manage for distance learning. Therefore, online classes for young children should be explicitly tailored and consider children's and parents' needs. Examples of possible considerations include young children's technology fluency (e.g., what they can and cannot do, what kind of external help they need, and who can provide that help in what form), their attention span (e.g., how long a meeting should be, the ways to keeping children interested and focused), and who should be responsible for helping children keep up with schooling (e.g., what are the reasonable expectations for teachers and parents, to what extent parents can be involved, and what if parents do not have the necessary time, knowledge, and technical skills to provide support). 
5.2.1 Connection to Parent Roles. The inconsistency in some parents' adopted facilitation practices and their belief about the division of labor between teachers and parents in children's education does not necessarily mean our identified facilitation practices are completely new or have never been performed by parents before the pandemic. Instead, some parents were compelled to exercise some facilitation practices that they would not do very often before the pandemic like sitting down together in children's classes. Therefore, we further connect our identified facilitation practices to parent role literature in this subsection. As shown in the most right column of Table 2, our four categories of facilitation practices (i.e., "Designing learning," "Finding resources," "Managing," and "Teaching") overlap with some parent roles in teenagers' development of technology fluency [3] and young children's learning with computational toys and kits [61]. More specifically, the "Designing learning" pattern shares a similar spirit with the "Scaffolder" [61] in which parents guide children's interaction with technologies into meaningful directions; "Finding resources" aligns with the "Resource provider" [3] as well as "Gatekeeper" [61], where parents explore and test resources to support children's learning; "Managing" overlaps with several roles, including [61]: "Enforcer" where parents manage children's media time and set play rules, "Logistics supporter" where parents provide logistics support like setting up technologies, and "Spectator" where parents observe children's interaction with technologies and offer help when needed; "Teaching" is similar to "Teacher" [3, 61] (i.e.,parents teach children how to use technologies and new knowledge) and overlaps with "Collaborator" $[3,61]$ in which parents join children's projects (and schoolwork in this study).

In addition to these overlaps, there are some differences that distinguish our study from these past studies of parent roles. First, the parent role studies (namely $[3,61]$ ) and this study are performed in different contexts, e.g., informal learning settings $[3,61]$ versus formal + informal learning settings (this study), supporting learning under a crisis (this study) versus under normal circumstances $[3,61]$, high-SES [3, 61] versus low-SES (this study) families. Second, even within similar facilitation patterns, each study highlights different aspects of how parents are involved. For example, parents under "Designing learning" in this study created learning tasks for children while a "Scaffolder" parent in [61] would suggest project ideas for children to try, and a "Spectator" parent in [61] may take a more passive observation of children's play with technologies while a "Managing" parent in our study may more aggressively and closely monitor their children's participation in online classes. Therefore, all these studies together contribute to a more comprehensive understanding of parental facilitation for children's technology-based learning. Third, our findings provide details into concrete parental facilitation practices for children's technology-based learning during a difficult pandemic time, which are valuable for educational practitioners and technology designers to ideate and improve remote learning experiences and technologies in preparation for future unexpected interruptions. These findings will also be relevant post-pandemic as children continue to engage in technology-based learning with families. Fourth, we identified parental facilitation practices that are not specified in parent-role literature, e.g., parents co-created learning schedules with children, stepped back from children's learning to create space for and encourage their independent learning, and helped address children's emotional difficulties in learning. These are important facilitation strategies as parents' other facilitation practices like teaching children new knowledge and finding learning resources. Taken together, our study advances the parent role literature by contributing new understanding of parental facilitation practices of children's technology-based learning from nondominant families as seen during a global pandemic crisis.

5.2.2 Connection to Parental Facilitation Practices from Nondominant Families. The aforementioned parental roles in children's learning with technologies are situated in the context of affluent families. To deepen the understanding of parents' facilitation practices during the pandemic, 
we further connect our findings to parental involvement in children's education reported from nondominant families before the pandemic. The comparison shows that nondominant parents were already exercising many of the facilitation practices we identified during the pandemic for their children's learning and technology use before the pandemic. These practices include (1) finding educational resources and brokering learning opportunities for children, such as searching learning resources for children's homework online or through their own network [8,32, 58]; (2) encouraging and scaffolding children's learning activities, e.g., suggesting project ideas for children and encouraging creative media creation [8,32]; (3) teaching children academic knowledge and technical skills, e.g., providing instructions on homework and photography skills [25, 32]; (4) co-learning and co-engaging with media technologies, e.g., collectively searching information and reading e-books together $[8,32,39]$; as well as (5) managing children's learning and interaction with technologies, such as checking children's schoolwork progress and limiting device access $[8,25,44]$ Such similarities suggest that nondominant parents continued their daily facilitation practices for children's learning into the pandemic. However, as discussed above, some new facilitation practices were necessitated by distance learning because what was generally taken care of by schools and teachers before the pandemic now had been overloaded onto parents. As such, we were able to identify some facilitation practices that are not often seen in nondominant family literature before the pandemic, i.e., creating learning tasks and schedules for children, participating in children's online learning, monitoring children's class participation, providing emotional support, helping review school work, seeking help from teachers for technical and academic problems, self-educating technical skills to provide support, and coordinating digital resources for learning.

Taken together, the above comparison between our findings and the parental involvement reported in parent-role literature and literature on nondominant families provides insights into how parents have been adjusting their facilitation strategies during a crisis. These identified similarities and differences demonstrate that the parental facilitation patterns identified in our study have a high level of comprehensiveness. Therefore, other researchers can use our findings as a starting point to examine and understand parental involvement in children's use of other educational media. In addition, the parental facilitation practices highlighted in our study may also benefit nondominant families by informing the improvement and design of remote learning experiences and tools that better consider parents' involvement and family needs as remote learning might become more prevalent in the future.

5.2.3 Reflection on the Framing of Families from Nondominant Groups. In the related work sections ( $2.2 \& 2.3)$ and in the findings, we present many challenges that families from non-dominant groups and our participants faced in supporting their children's learning with technologies. However, we are not arguing that parents from non-dominant groups are incapable of supporting their children's learning. Some of these challenges can also be found in more affluent families, e.g., lacking the needed knowledge to scaffold children's learning [61]. By highlighting the challenges, we want to call for more attention from educators, policymakers, and technology designers on how to better address the issues caused by the designs of learning experiences, policies, and technologies, especially for non-dominant families who have been disproportionately impacted by the pandemic $[50,53]$. Importantly, our findings also feature the strengths and resilience of the participants when facing challenges and uncertainties, as well as the various strategies they took up to continue facilitating productive learning experiences for their children, such as helping their children keep up with school schedules and providing logistical assistance for remote classes Such rich learning experiences and parental involvement should not be erased or dimmed by the reported challenges. 


\subsection{Design Implications for Learning Technologies}

Reflecting on parental facilitation practices of children's technology-based learning experiences during the pandemic and the challenges facing parents and children, we present three implications for designing learning technologies that address some of parents' and children's needs.

Designing for existing technological resources. Some families had limited technological resources to support their children's learning with technology, including not having necessary (and often assumed) equipment like dedicated laptops for each child or quality WIFI. To that end, we call for more attention to designing learning experiences, programs, and tools based on families' existing technological resources (e.g., televisions and smartphones), or "leveraging everyday tech as a significant asset" [6], such that parents do not have to pay for extra devices but can use the resources they already have. For example, meeting platforms and learning management tools may consider supporting running on television systems in the future. Designing technology-based opportunities to bridge digital divides is not just about providing access but also needs to acknowledge the costs accompanying digital access like maintenance costs [38]. Leveraging existing technological resources can both lower the barrier to digital access and reduce the accompanying cost.

Designing for child-centered interactions. Our findings show that young children generally needed additional support with manipulating technologies, such as logging in and out of online classes and submitting assignments. We suggest that technologies for learning (e.g., meeting platforms and learning management systems) can incorporate ways of interaction that empower children to be able to engage in an independent learning experience. Some examples include automatically logging children in and out of a meeting, adopting more child-friendly identity-verification processes (e.g., voice and gesture verification) rather than typing usernames and passwords, and providing tutorials that are easy and interesting for children to follow (e.g., animations) instead of presenting plain text that requires parents help to read. Note that we are not arguing to design technologies that keep out of parent involvement, but to free parents from endeavors like manipulating learning tools where children can have more independence. Parents are important facilitators of their children's learning, with or without the pandemic. In addition to considering children's capabilities, we see the need to design resources for parents to scaffold children's technology use and support their learning progress, e.g., adding a parent account for children's learning and meeting tools and ways to sharing credentials with guardians.

Designing for social interactions. A common challenge parents mentioned during distance learning was that their children mostly acted as listeners and lacked interactions with teachers and peers. In addition to incorporating more social and collaborative activities into the class, technologies can also play a role in promoting interactions between teachers, students, and parents. For example, meeting tools can include some built-in ice-breaker activities and add functions to facilitate class discussion, e.g., a button that each student can press to randomly pick another student for sharing ideas or presenting work. However, when adding new functions for existing learning tools or developing new tools, it is important for us researchers, designers, and developers to deeply consider and avoid potential privacy, social, and ethical issues that might arise for children, parents, and teachers.

\section{CONCLUSION}

In this work, we conducted semi-structured interviews with 22 parents from nondominant groups to investigate the kinds of technology-based learning experiences their young children engaged in during the pandemic, how parents facilitated these learning experiences, and what challenges parents and children encountered. Overall, children engaged in four types of technology-based 
learning experiences, including online schooling, watching educational videos, learning with educational apps and kits, as well as developing computer fluency. Parents performed a variety of practices to facilitate these learning experiences, which we classify into four categories: designing learning, finding resources, managing, and teaching. These facilitation patterns contribute new empirical evidence to and expand the theoretical understanding of parental involvement in children's learning with media and technologies. However, various challenges also emerged during children's learning, such as low-quality online classes, high teacher expectations that mismatched those of parents, and parents' lacking sufficient resources to support their children. Particularly, we call for attention to issues of equity in distance learning, such as unequal access to learning resources and quality education. Finally, we summarized three implications for designing technologies for learning, which includes designing for existing technological resources, child-centered interactions, and social interactions. Future research can continue to examine children's learning experiences during the pandemic from different perspectives (e.g., how children themselves perceive their experiences and how teachers have been organizing learning for students) and improve the current technologies for distance learning to provide a more productive learning experience for children.

\section{ACKNOWLEDGMENTS}

The authors thank the participants for sharing their experiences and insights with us. This project was made possible in part by the Institute of Museum and Library Services (LG-96-17-0176-17).

\section{REFERENCES}

[1] Morgan G. Ames, Janet Go, Joseph Jofish Kaye, and Mirjana Spasojevic. 2011. Understanding technology choices and values through social class. In Proceedings of the ACM 2011 conference on Computer supported cooperative work (CSCW '11). ACM, Hangzhou, China, 55-64.

[2] Rafael Ballagas, Thérèse E. Dugan, Glenda Revelle, Kochi Mori, Maria Sandberg, Janet Go, Emily Reardon, and Mirjana Spasojevic. 2013. Electric agents: Fostering sibling joint media engagement through interactive television and augmented reality. In Proceedings of the ACM Conference on Computer Supported Cooperative Work, CSCW. 225-235.

[3] Brigid Barron, Caitlin Kennedy Martin, Lori Takeuchi, and Rachel Fithian. 2009. Parents as Learning Partners in the Development of Technological Fluency. International fournal of Learning and Media 1, 2 (2009), 55-77.

[4] Virginia Braun and Victoria Clarke. 2006. Using thematic analysis in psychology. Qualitative Research in Psychology 3 , 2 (2006), 77-101.

[5] Kathy Charmaz. 2006. Constructing Grounded Theory: A Practical Guide through Qualitative Analysis. SAGE Publications, Inc. 224 pages.

[6] Alexander Cho, Roxana G. Herrera, Luis Chaidez, and Adilene Uriostegui. 2019. The "Comadre" Project: An Asset-Based Design Approach to Connecting Low-Income Latinx Families to Out-of-School Learning Opportunities. In Proceedings of the 2019 CHI Conference on Human Factors in Computing Systems (CHI '19). ACM, Glasgow, Scotland, UK, 1-14.

[7] Lynn Schofield Clark. 2011. Parental Mediation Theory for the Digital Age. Communication Theory 21, 4 (2011), 323-343.

[8] Betsy Disalvo, Parisa Khanipour Roshan, and Briana Morrison. 2016. Information seeking practices of parents: Exploring skills, face threats and social networks. In Proceedings of the 2016 CHI Conference on Human Factors in Computing Systems (CHI '16). ACM, San Jose, CA, USA, 623-634.

[9] Jill J. Francis, Marie Johnston, Clare Robertson, Liz Glidewell, Vikki Entwistle, Martin P. Eccles, and Jeremy M. Grimshaw. 2010. What is an adequate sample size? Operationalising data saturation for theory-based interview studies. Psychology and Health 25, 10 (2010), 1229-1245. https://doi.org/10.1080/08870440903194015

[10] Bruce Fuller, José Ramon Lizárraga, and James H. Gray. 2014. Digital Media and Latino Families: New Channels for Learning, Parenting, and Local Organizing. Technical Report. ERIC. 57 pages. https://eric.ed.gov/?id=ED555583

[11] Claudia Galindo and Sean F Reardon. 2006. Hispanic students' educational experiences and opportunities during kindergarten. Technical Report. Tempe, AZ: National Task Force on Early Childhood Education for Hispanics. 38 pages. https://cepa.stanford.edu/sites/default/files/hispanic\{_\}experience.pdf

[12] Radhika Garg and Subhasree Sengupta. 2019. "When you can do it, why can't I?": Racial and socioeconomic differences in family technology use and non-use. Proceedings of the ACM on Human-Computer Interaction 3, CSCW (2019), 22.

[13] Janet Go, Rafael Ballagas, and Mirjana Spasojevic. 2012. Brothers and Sisters at Play: Exploring Game Play with Siblings. In Proceedings of the ACM 2012 conference on Computer Supported Cooperative Work. ACM, Seattle, Washington,

Proc. ACM Hum.-Comput. Interact., Vol. 5, No. CSCW2, Article 307. Publication date: October 2021. 
USA, 739-748.

[14] Jessica Grose. 2020. Burnt Out on Home Schooling? https://www.nytimes.com/2020/05/13/parenting/coronavirusremote-learning-burn-out.html?referringSource=articleShare

[15] Holly M Grover. 2016. Where Cultures Collide: Hispanic Family Involvement in Education Among Different Socioeconomic Groups. Ph.D. Dissertation. https://tigerprints.clemson.edu/all\{_\}dissertations/1843

[16] Kris D. Gutiérrez, P. Zitlali Morales, and Danny C. Martinez. 2009. Re-mediating Literacy: Culture, Difference, and Learning for Students From Nondominant Communities. Review of Research in Education 33, 1 (2009), 212-245. https://doi.org/10.3102/0091732X08328267

[17] Richard Heeks. 2002. Information systems and developing countries: Failure, success, and local improvisations. The information society 18,2 (2002), 101-112.

[18] Brianna Hightower and Ellen Wartella. 2019. Exploring Parent Use of Early STEM Media to Inform Design for Children. In Proceedings of the 18th ACM International Conference on Interaction Design and Children. ACM, Boise, ID, USA, 102-108.

[19] Mizuko Ito, Sonja Baumer, Matteo Bittanti, Danah Boyd, Rachel Cody, Becky Herr-Stephenson, Heather A. Horst, Patricia G. Lange, Dilan Mahendran, Katynka Z. Martínez, C. J. Pascoe, Dan Perkel, Laura Robinson, Christo Sims, and Lisa Tripp. 2013. Hanging Out, Messing Around, and Geeking Out: Kids Living and Learning with New Media. The MIT Press. 440 pages.

[20] Hee Jhee Jiow, Sun Sun Lim, and Julian Lin. 2017. Level Up! Refreshing Parental Mediation Theory for Our Digital Media Landscape. Communication Theory 27, 3 (2017), 309-328.

[21] Stephanie T. Jones, Melissa Perez, Sarah P. Lee, Kira Furuichi, and Marcelo Worsley. 2019. Facilitation in an intergenerational making activity: How facilitative moves shift across traditional and digital fabrication. In Proceedings of the 18th ACM International Conference on Interaction Design and Children, IDC 2019. Boise, ID, USA, 237-245.

[22] Vikki Katz and Michael Levine. 2015. Connecting to learn: Promoting digital equity for American's Hispanic families. Technical Report. The Joan Ganz Cooney Center at Sesame Workshop, New York. 30 pages.

[23] Vikki S Katz. 2010. How Children of Immigrants Use Media to Connect Their Families to the Community: The case of Latinos in South Los Angeles. Fournal of Children and Media 4, 3 (2010), 298-315.

[24] Vikki S Katz. 2014. Kids in the Middle: How Children of Immigrants Negotiate Community Interactions for Their Families. Rutgers University Press, New Brunswick, NJ. 192 pages.

[25] Vikki S. Katz and Carmen Gonzalez. 2016. Community Variations in Low-Income Latino Families' Technology Adoption and Integration. American Behavioral Scientist 60, 1 (2016), 59-80.

[26] Vikki S. Katz, Meghan B. Moran, and Carmen Gonzalez. 2018. Connecting with technology in lower-income US families. New Media and Society 20, 7 (2018), 2509-2533.

[27] J Richard Landis and Gary G Koch. 1977. The Measurement of Observer Agreement for Categorical Data. Biometrics 33, 1 (1977), 159-174.

[28] Annette Lareau. 2011. Unequal childhoods: Class, race, and family life. Univ of California Press.

[29] Lation Decisions and Abriendo Puertas/Opening Doors. 2020. Latino Parent Voices: What Our Families Need Now. Technical Report. 16 pages. https://nationalsurvey.ap-od.org/

[30] J Lee and B Barron. 2015. Aprendiendo en Casa: Media as a Resource for Learning among Hispanic-Latino Families. A Report of the Families and Media Project. Technical Report. The Joan Ganz Cooney Center at Sesame Workshop, New York. 46 pages. https://eric.ed.gov/?id=ED555578

[31] Dafna Lemish and Nelly Elias. 2020. "We Decided We Don't Want Children. We Will Let Them Know Tonight": Parental Humor on Social Media in a Time of Coronavirus Pandemic. International fournal of Communication 14 (2020), 5261-5287.

[32] Amber Maria Levinson and Brigid Barron. 2018. Latino immigrant families learning with digital media across settings and generations. Digital Education Review 33 (2018), 150-169.

[33] Sonia Livingstone and Ellen J. Helsper. 2008. Parental mediation of children's internet use. fournal of Broadcasting and Electronic Media 52, 4 (2008), 581-599.

[34] Bethany Mandel. 2020. Distance Learning Isn’t Working. https://www.theatlantic.com/ideas/archive/2020/04/justgive-distance-learning/610222/?campaign_id=118\&emc=edit_ptg_20200513\&instance_id=18419\&nl=nytparenting\&regi_id=93258761\&segment_id=27510\&te=1\&user_id=bd0b3fca75f9c8cebb614224a23f5462

[35] Gary Marsden, Robert Cherry, and Alan Haefele. 2002. Small screen access to digital libraries. In CHI '02 Extended Abstracts on Human Factors in Computing Systems. Minneapolis, Minnesota, USA, 786-787.

[36] Bruce K. Messinger. 2016. Opportunity for All? Technology and Learning in Lower-Income Families. Technical Report. The Joan Ganz Cooney Center at Sesame Workshop, New York. 48 pages. https://eric.ed.gov/?id=ED574416

[37] Peter Nikken and Jeroen Jansz. 2014. Developing scales to measure parental mediation of young children's internet use. Learning, Media and Technology 39, 2 (2014), 250-266. 
[38] Lucy Pei and Roderic Crooks. 2020. Attenuated Access: Accounting for Startup, Maintenance, and Affective Costs in Resource-Constrained Communities. In CHI '20: Proceedings of the 2020 CHI Conference on Human Factors in Computing Systems. Honolulu, HI, USA, 1-15.

[39] Laura R. Pina, Carmen Gonzalez, Carolina Nieto, Wendy Roldan, Edgar Onofre, and Jason C. Yip. 2018. How Latino children in the U.S. engage in collaborative online information problem solving with their families. Proceedings of the ACM on Human-Computer Interaction 2, CSCW (2018).

[40] Hayes Raffle, Glenda Revelle, Koichi Mori, Rafael Ballagas, Kyle Buza, Hiroshi Horii, Jofish Kaye, Kristin Cook, Natalie Freed, Janet Go, and Mirjana Spasojevic. 2011. Hello, is grandma there? Let's read!: StoryVisit: Family video chat and connected e-books. In CHI '11: Proceedings of the SIGCHI Conference on Human Factors in Computing Systems. Vancouver, BC, Canada, 1195-1204.

[41] Justin Reich. 2020. Twitter Thread: Lessons Learned from the Lived Experiences of Teachers during the 2020 Pandemic. https://twitter.com/bjfr/status/1343957217507205120?s=20

[42] Justin Reich, Christopher J. Buttimer, Farah Faruqi Coleman, Dan Richard D. Colwell, and Laura R. Larke. 2020. What's Lost, What's Left, What's Next: Lessons Learned from the Lived Experiences of Teachers During the 2020 Novel Coronavirus Pandemic. Technical Report. EdArXiv. 28 pages. https://doi.org/10.35542/osf.io/8exp9

[43] Justin Reich and Mizuko Ito. 2017. From Good Intentions to Real Outcomes: Equity by Design in Learning Technologies. Technical Report. Digital Media and Learning Research Hub, Irvine, CA. 1-19 pages. http://creativecommons.org/ licenses/by/3.0/

[44] Parisa Khanipour Roshan, Maia Jacobs, Michaelanne Dye, and Betsy DiSalvo. 2014. Exploring how parents in economically depressed communities access learning resources. In Proceedings of the International ACM SIGGROUP Conference on Supporting Group Work. ACM, Sanibel Island, FL, USA, 131-141.

[45] Ofir Sadka and Oren Zuckerman. 2017. From Parents to Mentors: Parent-Child Interaction in Co-Making Activities. In Proceedings of the 2017 Conference on Interaction Design and Children. 609-615.

[46] Kiley Sobel, Arpita Bhattacharya, Alexis Hiniker, Jin Ha Lee, Julie A. Kiemtz, and Jason C. Yip. 2017. "It wasn’t really about the Pokémon": Parents' Perspectives on a Location-Based Mobile Game. In Proceedings of the 2017 CHI Conference on Human Factors in Computing Systems. ACM, Denver, Colorado, USA, 1483-1496.

[47] Kiley Sobel, Kate Yen, Yi Cheng, Yeqi Chen, and Alexis Hiniker. 2019. No touch pig! Investigating child-parent use of a system for training executive function. In Proceedings of the 18th ACM International Conference on Interaction Design and Children, IDC 2019. 339-351.

[48] Lori Takeuchi and Reed Stevens. 2011. The New Coviewing: Designing for Learning through foint-Media Engagement Technical Report. The Joan Ganz Cooney Center at Sesame Workshop. 75 pages. https://www.joanganzcooneycenter org/wp-content/uploads/2011/12/jgc_coviewing_desktop.pdf

[49] Emeline Therias, Jon Bird, and Paul Marshall. 2015. Más tecnología, más cambio? Investigating an educational technology project in rural Peru. In CHI '15: Proceedings of the 33rd Annual ACM Conference on Human Factors in Computing Systems, Vol. 2015-April. Seoul, Korea, 447-456.

[50] United Nations. 2020. Policy Brief: Education during COVID-19 and beyond. Technical Report August. https: //reliefweb.int/report/world/policy-brief-education-during-covid-19-and-beyond-august-2020

[51] United States Census Bureau. 2019. U.S. Median Household Income Up in 2018 From 2017. https://www.census.gov/ library/stories/2019/09/us-median-household-income-up-in-2018-from-2017.html

[52] United States Census Bureau. 2020. Race and Hispanic Origin. https:/www.census.gov/quickfacts/fact/table/US/ PST045219

[53] USA Centers for Disease Control and Prevention. 2020. COVID-19 in Racial and Ethnic Minority Groups. https: //www.cdc.gov/coronavirus/2019-ncov/need-extra-precautions/racial-ethnic-minorities.html

[54] Patti M Valkenburg, Marina Krcmar, Allerd L Peeters, and Nies M Marseille. 1999. Developing a scale to assess three styles of television mediation: "Instructive mediation," "restrictive mediation," and "social coviewing". fournal of Broadcasting \& Electronic Media 43, 1 (1999), 52-66.

[55] Rojin Vishkaie. 2020. The pandemic, war, and sanctions: building resilience for the digital divide in education. Interactions 27, 4 (2020), 34-36

[56] S Craig Watkins and Alexander Cho. 2018. The digital edge: How Black and Latino youth navigate digital inequality. NYU Press.

[57] Marisol Wong-Villacres, Hayley Evans, Danielle Schechter, Betsy DiSalvo, and Neha Kumar. 2019. Consejero automatico: Chatbots for supporting Latino parents' educational engagement. In Proceedings of the Tenth International Conference on Information and Communication Technologies and Development (ICTD '19). Ahmedabad, India, 2-6.

[58] Marisol Wong-villacres, Neha Kumar, and Betsy Disalvo. 2019. The Parenting Actor-Network of Latino Immigrants in the United States. In Proceedings of the 2019 CHI Conference on Human Factors in Computing Systems (CHI '19). ACM Glasgow, Scotland, UK, 1-12. 
[59] Marisol Wong-Villacres, Neha Kumar, and Betsy Disalvo. 2019. The work of bilingual parent-education liaisons: Assembling information patchworks for immigrant parents. Proceedings of the ACM on Human-Computer Interaction 3 , CSCW (2019), 24.

[60] Sarita Yardi and Amy Bruckman. 2012. Income, Race, and Class: Exploring Socioeconomic Differences in Family Technology Use. In Proceedings of the SIGCHI Conference on Human Factors in Computing Systems (CHI '12). ACM, Austin, Texas, USA, 3041-3050.

[61] Junnan Yu, Chenke Bai, and Ricarose Roque. 2020. Considering Parents in Coding Kit Design: Understanding Parents' Perspectives and Roles. In Proceedings of the 2020 CHI Conference on Human Factors in Computing Systems. ACM, Honolulu, HI, USA, 1-14.

[62] Gema Zamarro, Francisco Perez-Arce, and Maria Jose Prados. 2020. Gender Differences in the Impact of COVID19. Technical Report. University of Southern California. 1-9 pages. https://dornsife.usc.edu/news/stories/3234/ understanding-coronavirus-survey-gender-disparities/

[63] Maria Estela Zarate. 2007. Understanding Latino Parental Involvement in Education. Technical Report. ERIC. 20 pages. https://eric.ed.gov/?id=ED502065

Received October 2020 ; revised January \& April 2021 ; accepted May 2021 